\title{
Ultrasonography-triggered diagnosis of putrid, ulcero-phlegmonous, hemorrhagic appendicitis and periappendicitis with an atypical symptom pattern: a case report
}

\author{
Hagen Frickmann ${ }^{1,2^{*}}$ and Sven A. Jungblut ${ }^{3}$
}

\begin{abstract}
Background: Asymptomatic and oligosymptomatic appendicitis are rare and challenging diagnoses that should not be missed.

Case presentation: A young female patient presented with mild to moderate pain in the middle and lower abdomen, and the results of physical examination, including digital rectal examination, were otherwise non-contributory. Ultrasonography demonstrated a marked increase of the outer appendiceal diameter up to $12 \mathrm{~mm}$ and a trace of free liquid around the terminal ileum. Subsequent surgical exploration and histological examination allowed for a final diagnosis of putrid, ulcero-phlegmonous, hemorrhagic appendicitis and periappendicitis.

Conclusions: Ultrasonography is increasingly used for the diagnosis of appendiceal inflammation, particularly in military medical settings. Increases in the outer appendiceal diameter up to $>6 \mathrm{~mm}$ under compression have recently been demonstrated to be indicative of acute appendicitis. At a minimum, in cases with doubtful physical examination results, ultrasonography should be considered as an element in the diagnosis of acute appendicitis.
\end{abstract}

Keywords: Acute appendicitis, Ultrasound, Oligosymptomatic, Surgery

\section{Background}

The management of appendicitis is a standard situation for military surgeons. Among active component members of the U.S. Armed Forces, the overall incidence of appendicitis was 18.4 per 10,000 person-years between 2002 and 2011 [1]. Acute appendicitis is also among the frequent causes of surgical interventions during deployment $[2,3]$. The high perforation rates abroad [2] typically result from incorrect initial diagnoses or treatments. During the missions of the U.S. Armed Forces in Iraq and Afghanistan, appendicitis was among the most frequent causes of medical evacuations [1].

\footnotetext{
*Correspondence: frickmann@bni-hamburg.de

'Department of Tropical Medicine at the Bernhard Nocht Institute, German

Armed Forces Hospital of Hamburg, Hamburg, Germany

${ }^{2}$ Institute for Microbiology, Virology and Hygiene, University Medicine

Rostock, Rostock, Germany

Full list of author information is available at the end of the article
}

The use of ultrasound scanning of the abdomen for the diagnosis of appendicitis has previously been evaluated. In cases of acute appendicitis, the outer appendiceal diameter increases to $7.9 \pm 2.0 \mathrm{~mm}$ compared with a typical outer appendiceal diameter value of $4.5 \pm 1.2 \mathrm{~mm}$ for healthy populations. Further, periappendiceal inflamed fat is frequently detected by ultrasound scanning in patients with appendicitis [4].

Here, we describe a rare case of progressed appendicitis that nevertheless presented with mild to moderate symptoms and was diagnosed based only on ultrasound scanning results.

\section{Case presentation Clinical history}

A 21-year old female patient presented at the emergency department of a hospital with progressive pain in the middle and lower right abdomen, nausea and vomiting. The 
symptoms began $12 \mathrm{~h}$ prior to her arrival. Defecation and stool consistency were non-contributory. Fever and chills were denied. Lactose intolerance was the only reported pre-existing condition.

\section{Physical examination}

The rectal temperature of the patient was $37.4{ }^{\circ} \mathrm{C}$. The patient was alert and oriented. The described pain in the middle and lower right abdomen could be induced by pressure. Apart from these findings, the physical examination was non-contributory.

Specifically, the patient's abdomen was soft, and there were no signs of guarding or peritoneal signs. Auscultation of the abdomen was non-contributory. A digital rectal examination did not provoke any pain in the recto-uterine pouch. The sphincter tone was normal. The stool was brown and did not exhibit any signs of blood or viscous secretions. The reported pain was noticeably decreased following novaminsulfon infusion. Overall, the patient appeared to be only marginally compromised, and dismissal from the emergency department was therefore considered.

\section{Routine laboratory results}

A marked increase in the white blood cell count to $17.8 \times 10^{9} / \mathrm{L}$ (ref.: $3.8 \times 10^{9} / \mathrm{L}-9.8 \times 10^{9} / \mathrm{L}$ ) was observed, whereas the $\mathrm{C}$-reactive protein level was noncontributory at $2.4 \mathrm{mg} / \mathrm{L}$ (ref.: <5). A slightly increased free tetraiodothyronine level of $15.7 \mathrm{pmol} / \mathrm{L}$ (ref.: 7.7 14.2) was observed as an incidental finding. All other assessed laboratory parameters were normal.

\section{Ultrasonography of the abdomen}

There was a trace of free fluid around the terminal ileum. Further, an intestinal cockade sign was visible, and the size of the appendix wall was increased to $3 \mathrm{~mm}$ (Fig. 1). In the distal parts of the appendix, the outer appendiceal diameter was increased up to $12 \mathrm{~mm}$.

The overall accuracy of ultrasonography for the identification of acute appendicitis was recently estimated at approximately $90 \%$ based on an analysis of a small cohort of 60 patients [5]. In this study, an appendiceal diameter $>6 \mathrm{~mm}$ under compression was considered to be the cut-off point for a reliable diagnosis [5]. On French submarines, ultrasonography of the abdomen is routinely performed in cases of suspected appendiceal abscesses, and the accuracy is high [6].

\section{Diagnosis and therapy}

Based on the ultrasound results, a diagnosis of acute appendicitis was made. Laparoscopic surgical intervention allowed for the extirpation of an inflamed, phlegmonous appendix (Fig. 2).

The operation and postoperative management were without any complications.

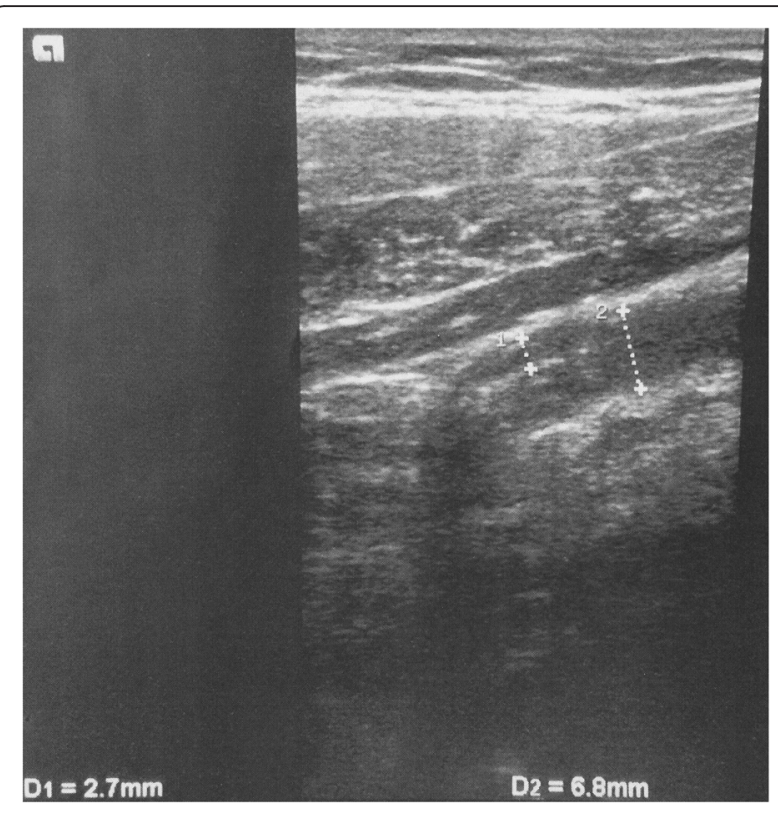

Fig. 1 Ultrasonography of the abdomen. An ultrasound-triggered suspicion of acute appendicitis was based on the free liquid around the terminal ileum, the intestinal cockade sign and the increase of the wall thickness of the proximal appendix to $3 \mathrm{~mm}$. D1 $(2.7 \mathrm{~mm})$ ist equal to the increased wall thickness with weak echo signal intensity. D2 $(6.8 \mathrm{~mm})$ is equal to the diameter of the inflamed appendix in its proximal part

\section{Histological assessment}

Putrid, ulcero-phlegmonous, hemorrhagic appendicitis and peri-appendicitis with putrid fibrinous serositis and fecal impaction were diagnosed. A partial spread of the inflammatory process beyond the surgical margins was observed.

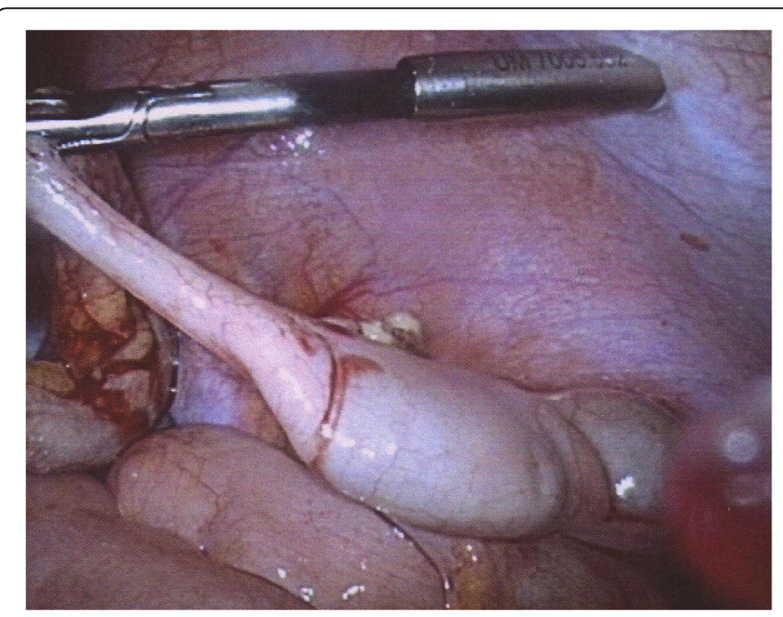

Fig. 2 Intraoperative situs with an inflamed phlegmonous appendix. The suboptimal shooting angle and range make the observation of the anatomical relations difficult, which reflects the real-life surgical situation 


\section{Conclusions}

Skilled use of abdominal ultrasonography can serve critical diagnostic purposes for forward deployed troops when other modalities, such as computed tomography, are not available due to the austere settings. In such situations, abdominal ultrasonography is particularly important for young females for whom the differential diagnoses of abdominal and pelvic pain are much broader $[7,8]$ and including gynecological diagnoses, such as pelvic inflammatory disease $[9,10]$, torsion, ectopic pregnancy [11], cystitis [12], other infections [13], and pelvic pain of unclear etiology [12].

The peculiarity of the present case is that ultrasonography provided the most important information for the diagnosis of appendicitis. Oligosymptomatic and asymptomatic cases of appendicitis are both rare [14] and challenging in terms of differential diagnosis. In the present case, mild to moderate symptoms without pain in the recto-uterine pouch were revealed by the physical examination despite an advanced inflammatory process that affected the patient's mesentery. Without the ultrasonography results, the patient, who presented with mild to moderate appendicitis, would have been sent home, and a watch-and-wait approach would have been employed. This approach might have resulted in perforation and the associated complications. However, ultrasonography demonstrated an increased appendiceal diameter that far exceeded the $>6 \mathrm{~mm}$ cut-off point that has recently been suggested [5]. Furthermore, a trace of free fluid around the terminal ileum was observed, which supported the diagnosis. Although the importance of ultrasound scanning for the diagnosis of appendicitis is well established, the fact that a severely progressed state of inflammation was associated with symptoms that were sufficiently mild that the patient would have been sent home without the ultrasound result is quite unusual and should be kept in mind.

Both computed tomography (CT) and ultrasound scanning (US) have been demonstrated to be useful modalities in the diagnosis of acute appendicitis. Both techniques are used to reduce the number of unnecessary surgical interventions [15], but US also has the advantage of providing results without exposure to ionizing radiation [15]. The use of US scoring systems can contribute to a reduction in the use of CT scanning while ensuring the diagnosis [16]. Nonvisualization of the appendix on US is a highly predictive sign of the absence of appendicitis with an accuracy of $94.3 \%$ [17], particularly in children when leukocytosis is absent [18]. The secondary signs of hyperemia, i.e., fluid collection and the presence of an appendicolith, exhibit $96 \%$ specificity and $88 \%$ accuracy for the presence of appendicitis in cases of otherwise equivocal ultrasound results [19]. Next to the visualizations of the appendix and periappendiceal fluid, an appendiceal diameter $>6 \mathrm{~mm}$, an appendix wall thickness $>2 \mathrm{~mm}$, and indirect associated signs, such as an increased white blood cell count and an increased polymorphonuclear percentage, are considered to be predictors of appendicitis [20]. However, perforations in cases of acute appendicitis are likely to go undetected based on US [21].

$\mathrm{CT}$ is the most accurate imaging modality for cases of suspected appendicitis and should be considered in cases of questionable US findings when a CT scanner is available [22]. If there are contraindications for the use of contrast enhancers, noncontrast $\mathrm{CT}$ also exhibits a high diagnostic accuracy for the detection of appendicitis [23]. The interpretation of scores based on a specific cutoff points, such as the Alvarado score, ease the standardized interpretation of CT results [22]. However, the ionizing radiation associated with $\mathrm{CT}$ is one of its disadvantages. Furthermore, even when $\mathrm{CT}$ is employed, the detection of perforation signs is not easy in the early stages of the process [24], particularly when an abscess and phlegmon are still absent. Potential perforation should be considered if extraluminal air bubbles, increased wall thickness, or the presence of an intraluminal fecalith are observed on CT imaging [25]. In cases of borderline appendix sizes, the combined detection of wall thickening and the absence of intraluminal air on CT imaging has been confirmed to be a reliable predictor of appendicitis [26]. Compared with US, CTmeasured appendiceal diameters may vary by $1-2 \mathrm{~mm}$, and this variation needs to be considered during the interpretation of the results [27]. Notably, the use of CT has not been demonstrated to be associated with better outcomes in patients with appendicitis [28, 29].

If ionizing radiation is to be avoided, magnetic resonance imaging involving gadolinium-enhanced and $\mathrm{T}_{2}$ weighted images has been demonstrated to be an expensive but useful alternative for the detection of acute appendicitis [30, 31]. Recently, the measurement of the elastic modulus values via shear wave elastography has been suggested as a new diagnostic approach for distinguishing between inflamed and normal appendices [32]. Larger studies would likely be useful to assess the clinical effects of this procedure.

In cases of less advanced oligosymptomatic appendicitis, colonscopy is an alternative procedure that might support the diagnosis [33]. In contrast, the diseaseassociated results of laboratory diagnostic procedures may be non-specific. Cyclic neutropenia has been described in a previous case of asymptomatic appendicitis [34]. In the presently described case, leukocytosis suggested the presence of an inflammatory process.

As demonstrated by a case of bilateral ureteral obstruction following asymptomatic appendicitis [35], the consequences of the delayed diagnoses of 
oligosymptomatic and asymptomatic appendicitis can be severe. Experience with ultrasonography of the abdomen may contribute to the prevention of similar unfavorable clinical courses.

\section{Consent}

Written informed consent for the publication of this case report and any accompanying images was obtained from the patient. A copy of the written consent is available for review by the Editor-in-Chief of this journal.

\section{Abbreviations}

$\mathrm{CT}$, computed tomography; US, ultrasound scanning

\section{Availability of data and materials}

All relevant data and materials are presented in the paper.

\section{Authors' contributions}

HF participated in the writing of the article. SAJ provided the clinical data and participated in the writing of the article. Both authors read and approved the final manuscript.

\section{Authors' information \\ HF is a consultant for medical microbiology, virology and infectious disease epidemiology. He works at the Department of Tropical Medicine at the Bernhard Nocht Institute of the German Armed Forces Hospital of Hamburg, Germany. SAJ is a consultant for internal medicine. He works as a general practitioner in his own practice "Praxis Dr. Jungblut" in Frankfurt/Main, Germany.}

\section{Competing interests}

The authors declare that they have no competing interests.

\section{Consent for publication}

Consent for publication has been obtained.

\section{Ethics approval and consent to participate}

Ethical clearance was not required for this retrospective case assessment in accordance with German law. Anonymous patient data were retrospectively assessed. No medical procedures were performed for study purposes. Accordingly, this case report did not fulfill the criteria for description as a scientific project involving humans according to $\S 9.2$ of the Law of the Association of Hamburg Physicians ("Hamburgisches Kammergesetz für Heilberufe"), and ethical counseling was not required according to $\S 15.1$ of the Professional Guidelines of Hamburg Physicians ("Berufsordnung für Hamburger Ärzte und Ärztinnen"). Due to the anonymous nature of the assessment, German data protection law ("Bundesdatenschutzgesetz") was not applicable.

\section{Author details}

'Department of Tropical Medicine at the Bernhard Nocht Institute, German Armed Forces Hospital of Hamburg, Hamburg, Germany. ${ }^{2}$ Institute for Microbiology, Virology and Hygiene, University Medicine Rostock, Rostock, Germany. ${ }^{3}$ Practice Dr. Jungblut, Frankfurt/Main, Germany.

Received: 9 November 2015 Accepted: 10 June 2016

Published online: 27 June 2016

\section{References}

1. [No authors listed]. Appendicitis and appendectomies, active and reserve components, U.S. Armed Forces, 2002-2011. MSMR. 2012;19:7-12.

2. Morrison CA, Greco DL, Torrington KG. Patterns of appendicitis at a forward-deployed United States Army Hospital: the Korea experience. Curr Surg. 2000;57:603-9.

3. Place RJ, Rush Jr RM, Arrington ED. Forward surgical team (FST) workload in a special operations environment: the 250th FST in Operation ENDURING FREEDOM. Curr Surg. 2003;60:418-22.
4. Yabunaka K, Katsuda T, Sanada S, Yatake H, Fukotomi T. Sonographic examination of the appendix in acute infectious enteritis and acute appendicitis. J Clin Ultrasound. 2008;36:63-6.

5. Hussain S, Rahman A, Abbasi T, Aziz T. Diagnostic accuracy of ultrasonography in acute appendicitis. J Ayub Med Coll Abbottabad. 2014;26:12-7

6. Hornez E, Gellie G, Entine F. Is there still a benefit to operate appendiceal abscess on board French nuclear submarines? Mil Med. 2009;174:874-7.

7. Hewitt GD, Brown RT. Acute and chronic pelvic pain in female adolescents. Med Clin North Am. 2000;84:1009-25.

8. Lamvu G, Steege JF. The anatomy and physiology of pelvic pain. J Minim Invasive Gynecol. 2006;13:516-22.

9. McNeeley Jr SG. Pelvic inflammatory disease. Curr Opin Obstet Gynecol. 1992:4:682-6.

10. Sweet RL. Treatment of acute pelvic inflammatory disease. Infect Dis Obstet Gynecol. 2011;2011:561909.

11. Economy KE, Laufer MR. Pelvic pain. Adolesc Med. 1999;10:291-304.

12. Wright Jr J, Albright TS, Gehrich AP, Dunlow SG, Lettieri CF, Buller JL. Pelvic pain presenting in a combat environment. Mil Med. 2006;171:841-3.

13. Faro S, Maccato M. Pelvic pain and infections. Obstet Gynecol Clin North Am. 1990:17:441-55.

14. Deming Sr JE. Asymptomatic appendicitis. Northwest Med. 1959;58:1562.

15. Reddan T, Corness J, Mengersen K, Harden F. Ultrasound of paediatric appendicitis and its secondary sonographic signs: providing a more meaningful finding. J Med Radiat Sci. 2016;63:59-66.

16. Fallon SC, Orth RC, Guillerman RP, Munden MM, Zhang W, Elder SC, et al. Development and validation of an ultrasound scoring system for children with suspected acute appendicitis. Pediatr Radiol. 2015;45:1945-52.

17. Ly DL, Khalili K, Gray S, Atri M, Hanbidge A, Thipphavong S. When the appendix is not seen on ultrasound for right lower quadrant pain: does the interpretation of emergency department physicians correlate with diagnostic performance? Ultrasound Q. 2016 [Epub ahead of print].

18. Cohen B, Bowling J, Midulla P, Shlasko E, Lester N, Rosenberg H, et al. The non-diagnostic ultrasound in appendicitis: is a non-visualized appendix the same as a negative study? J Pediatr Surg. 2015;50:923-7.

19. Partain KN, Patel A, Travers C, McCracken CE, Loewen J, Braithwaite K, et al. Secondary signs may improve the diagnostic accuracy of equivocal ultrasounds for suspected appendicitis in children. J Pediatr Surg. 2016. [Epub ahead of print].

20. Lam SH, Grippo A, Kerwin C, Konicki PJ, Goodwine D, Lambert MJ. Bedside ultrasonography as an adjunct to routine evaluation of acute appendicitis in the emergency department. West J Emerg Med. 2014;15:808-15.

21. Tseng P, Berdahl C, Kearl YL, Behar S, Cooper J, Dollbaum R, et al. Does right lower quadrant abdominal ultrasound accurately identify perforation in pediatric acute appendicitis? J Emerg Med. 2016;50:638-42.

22. Shogilev DJ, Duus N, Odom SR, Shapiro NI. Diagnosing appendicitis: evidence-based review of the diagnostic approach in 2014. West J Emerg Med. 2014;15:859-71.

23. Xiong B, Zhong B, Li Z, Zhou F, Hu R, Feng Z, et al. Diagnostic accuracy of noncontrast $C T$ in detecting acute appendicitis: a meta-analysis of prospective studies. Am Surg. 2015;81:626-9.

24. lacobellis F, ladevito I, Romano F, Altiero M, Bhattacharjee B, Scaglione M. Perforated appendicitis: assessment with multidetector computed tomography. Semin Ultrasound CT MR. 2016;37:31-6.

25. Verma R, Grechushkin V, Carter D, Barish M, Pryor A, Telem D. Use and accuracy of computed tomography scan in diagnosing perforated appendicitis. Am Surg. 2015;81:404-7.

26. Thompson AC, Olcott EW, Poullos PD, Jeffrey RB, Thompson MO, Rosenberg $J$, et al. Predictors of appendicitis on computed tomography among cases with borderline appendix size. Emerg Radiol. 2015;22:385-94.

27. Orscheln ES, Trout AT. Appendiceal diameter: CT versus sonographic measurements. Pediatr Radiol. 2016:46:316-21.

28. Bachur RG, Levy JA, Callahan MJ, Rangel SJ, Monuteaux MC. Effect of reduction in the use of computed tomography on clinical outcomes of appendicitis. JAMA Pediatr. 2015;169:755-60.

29. Miano DI, Silvis RM, Popp JM, Culbertson MC, Campbell B, Smith SR. Abdominal CT does not improve outcome for children with suspected acute appendicitis. West J Emerg Med. 2015:16:974-82.

30. Rosines LA, Chow DS, Lampl BS, Chen S, Gordon S, Mui LW, et al. Value of gadolinium-enhanced MRI in detection of acute appendicitis in children and adolescents. AJR Am J Roentgenol. 2014;203:w543-8. 
31. Kulaylat AN, Moore MM, Engbrecht BW, Brian JM, Khaku A, Hollenbeak CS, et al. An implemented MRI program to eliminate radiation from the evaluation of pediatric appendicitis. J Pediatr Surg. 2015;50:1359-63.

32. Cha SW, Kim IY, Kim YW. Quantitative measurement of elasticity of the appendix using shear wave elastography in patients with suspected acute appendicitis. PLoS One. 2014;9:e101292.

33. Petro M, Minocha A. Asymptomatic early acute appendicitis initiated and diagnosed during colonoscopy: a case report. World I Gastroenterol. 2005;11:5398-400.

34. Goldschneider KR, Forouhar FA. Cyclic neutropenia: a case of asymptomatic appendicitis. Ann Clin Lab Sci. 1989;19:429-34.

35. Green JT, Pham HT, Hollowell CP, Krongrad A. Bilateral ureteral obstruction after asymptomatic appendicitis. J Urol. 1997;157:2251.

Submit your next manuscript to BioMed Central and we will help you at every step:

- We accept pre-submission inquiries

- Our selector tool helps you to find the most relevant journal

- We provide round the clock customer support

- Convenient online submission

- Thorough peer review

- Inclusion in PubMed and all major indexing services

- Maximum visibility for your research

Submit your manuscript at www.biomedcentral.com/submit
Biomed Central 